Research Article

\title{
POTENTIAL ROLE OF MESENCHYMAL STEM CELLS IN TREATMENT OF STZ DIABETIC INDUCED RAT MODEL REFERRING TO HEPATORENAL PROTECTIVE EFFECTS
}

\author{
Ahmad K Hassan*, Ibrahim El Zaatary, Sherifa Hamed and Ossam A Abbas
}

Department of Zoology, Faculty of Science, Port Said University, Egypt

Article History: Received 14 ${ }^{\text {th }}$ July, 2019; Accepted 24 ${ }^{\text {th }}$ July, 2019; Published 01 August, 2019

\begin{abstract}
Diabetes is a complex chronic endocrinal distinguished with increased blood glucose level and insufficient insulin secretion and function. This disease is leading to many complications and considered as one of the most massive causes of mortality or morbidity around the world. The successful treatment of diabetes is how to regenerate pancreatic islets $\beta$-cells. The current study aimed to investigate the effect of mesenchymal stem cells (MSCs) transplantation as a new strategy for treatment of diabetes in Streptozotacin (STZ) induced diabetic male albino rats. To achieve this goal, thirty male albino rats (160-180 grams) were used in this work. Animals were divided into three groups; each of ten rats. Group I, Normal healthy control. Group II, STZ $(45 \mathrm{mg} / \mathrm{kg})$ induced diabetic group which left without treatment. Group III, STZ diabetic induced group and treated with MSC.s $(2 \times 106$ cells/rat) via penial vein. After six weeks of treatment, animals were sacrificed; blood samples for biochemical estimations and organs of pancreas, liver, and kidney were removed for histopathological examination. The results revealed that the diabetic group had significant increase in glucose, ALT, AST, ALP, MDA, creatinine, urea, LDL, TGs, and cholesterol levels in addition to significant decrease in insulin and HDL levels. After six weeks of MSCs transplantation, the treated group showed a significant amelioration in these biochemical parameters. Histopathological examination showed an improvement in the histological structure of pancreas, liver and kidney tissues in the MSCs treated group compared with the degeneration observed in the diabetic untreated group which was in accordance with the biochemical finding. In conclusion: treatment with MSC.s transplantation as a cell-therapy could restore pancreatic $\beta$-cell function and improved liver and kidney functions in diabetes as a new strategy for diabetes treatment. However, more studies at this field are required.
\end{abstract}

Keywords: MSCs; Diabetes; Hepatorenal; STZ; Rat

\section{INTRODUCTION}

Diabetes mellitus (DM) is a chronic disease distinguished with a massive and progressive devastation of pancreatic insulin secretory $\beta$-cells which give rise to insulin deficiency (Chhabra et al. 2013). The propagation of DM is increased rapidly all over the world probably due to ageing, increasing prevalence of obesity and sedentary lifestyle and as reported by the International Diabetes Federation at least 382 million individuals are suffering from diabetes and this number is likely to become more than 592 million by 2035 (Bhansali et al. 2015). In Egypt, the statistical data revealed that the prevalence of DM last 20 years is increased from $9.9 \%$ in the year 1995 to $10.2 \%$ in 2000 and prospected to be $13.3 \%$ in 2025 (Ahmed et al. 2017).

However, the complications of DM have developed health, economic and social life impacts on individuals, families, health systems and countries ( $\mathrm{Lv}$ et al. 2014). Cantarelli et al. (2015) had reported that the both types of diabetes, type 1 and type 2 , are recognized by a variable deficiency values in the mass of pancreatic beta-cell which leading to insulin insufficiency regarding the different pathogenic cause, autoimmunity in type 1 and may be insulin resistance in type
2. DM is leading to many health disturbances mainly glucose and fat metabolism disorders, in consequence fatty liver is the predominant frequent complication (Byrne et al. 2016).

The control of DM is very crucial and needs of diseasemodifying successful effective treatment and new therapeutic approaches rather than the currently used chemical derived drugs. The supplement with compatible donor of islets in order to transplantation purpose is very limited. For this reason, the researchers must seek another different source of implantation material to regenerate and restore $\beta$ cell activity (Lui et al. 2015, Franchi et al. 2014). Depending on this base, the cell-based therapies could be a new promising replacement strategic plan for diabetes treatment (Franchi et al., 2014).

Recently, the using of stem cells transplantation in clinical purposes is markedly increased (Cantarelli et al. 2015). Stem cells are undifferentiated cells and had the ability to transform into another type of cells, so would be a potential source of pancreatic islet $\beta$-cells, the insulin producing cells (Zhu et al. 2012). Regarding stem cells, mesenchymal stem cells (MSCs) are admitted as influential modulators for immune system and have possible therapeutic profits (Portha et al. 2011). There are an increased data showed that there are many therapeutic 
effects of MSCs not only rely on their differentiation ability to regenerate the damaged tissue, but also depend on their potency to modulate and activate endogenous progenitor cells (Hsiao et al. 2015).

The current study aimed to disclose the potential therapeutic role of mesenchymal stem cells transplantation in the treatment of DM and overcomes associate complications in streptozotacin (STZ) induced diabetic rat model. This aim was achieved by measurement of different biochemical and physiological parameters which were supported with histopathological investigations for pancreas, liver, and kidney organs.

\section{MATERIALS AND METHODS}

\section{Experimental animals}

A total number of 30 male adult albino rats weighting 160 $180 \mathrm{gm}$ were used in the current experimental study. They were obtained from the Animal House of Nile Center for Experimental Researches, Mansoura, Egypt. Animals were housed in separate metal cages, kept at a natural environmental (12 hrs Light/dark cycle), and were fed standard commercial pellets and supplied with fresh drinking water ad libitum through specific nipple. Animal maintenance and care were in accordance with recommended International Guiding Principles for Biochemical Research Involving Animals.

\section{Induction of diabetes}

The diabetic animal model was induced by a single intraperitoneal injection of STZ $(45 \mathrm{mg} / \mathrm{kg})$ body weight. It was immediately dissolved just before injection in freshly prepared $0.1 \mathrm{~mol} / \mathrm{L}$ citrate buffers $(\mathrm{pH} 4.5$ ) (Tariq et al. 2013). Injected animals were supplied with 5\% glucose rather than water at the first 24 hours to avoid the suddenly expected hypoglycemia due to released insulin from necrotic pancreatic beta cells. After three days of STZ injection, glucose concentration in blood samples obtained from tail vein were measured using glucose meter (Glucostar, Medland Co., Taiwan). Rats have blood glucose concentration more than $180 \mathrm{mg} / \mathrm{dl}$ were considered as diabetic.

\section{Isolation and preparation of MCCs}

Isolation and culturing of MSCs were done according to the method was described by Abdel Aziz et al. 2007. The animals were anesthetized by halothane, and then the skin of the rat was sterilized with $70 \%$ ethyl alcohol before cutting the skin. The femur and tibia were carefully dissected from adherent soft tissues. Then they were placed into sterilized beaker containing 70\% ethyl alcohol for $1-2 \mathrm{~min}$. The bones were put in Petri dish containing phosphate buffer saline 1X (PBS) (Hyclone, USA) for washing. The washed bones were taken to laminar air flow (Unilab Biological Safety Cabinet Class II, China) to extract the bone marrow (BM). The two ends of the bones were removed using sterile scissors. BM was harvested by flushing the tibia and femur with Dulbecco's modified Eagles medium (DMEM) (lonza, Belgium) supplemented with 10\% fetal bovine serum (FBS) (Lonza, Belgium) and 1\% antibiotic, antimycotic (penicillin streptomycin) (Lonza, USA). The marrow plugs were cultured in $20 \mathrm{ml}$ complete media and incubated at $37^{\circ} \mathrm{C}$ in
$5 \%$ humidified $\mathrm{CO}_{2}$ incubator (Shellab, USA) for 7-10 days as primary culture or upon formation of large colonies.

\section{Culturing of bone marrow stem cells}

The cells were cultured in $75 \mathrm{~cm}^{2}$ tissue culture flask containing 10-15 ml complete media in humidified incubator at $37^{\circ} \mathrm{C}$ in $5 \% \mathrm{CO}_{2}$ and $95 \%$ air (by volume). The cells were examined daily using inverted microscope (Olympus CKX41, USA) to follow up the cells growth. After $24 \mathrm{hrs,} \mathrm{the}$ old media was removed by aspiration using sterile pipette, the cells were then washed with $5 \mathrm{ml}$ PBS, and then 15 $\mathrm{ml}$ of complete media was added to the flask. MSCs were distinguished from other bone marrow cells by. The second exchange for media was done after 3-4 days. The cells take 4 weeks to be confluent and be ready for passaging. The media was changed twice a week (Aziz et al. 2007).

\section{Morphologic characterization of the expanded MSCs}

At the end of the expansion phase, the cells became homogenous, spindle shaped, fibroblast-like and arranged in monolayer (Figure 1).

\section{MSCs harvesting}

The cells attach themselves to the surface of tissue culture polystyrene flasks or dishes using proteins secreted by them. To dislodge cells from the flask, the protein bridge must be broken by proteolytic enzyme, trypsin. EDTA is often added to trypsin solutions. EDTA allows trypsin to work more efficiently. Cultured cells were washed with PBS solution, washed cells were resuspended in $1 \mathrm{ml}$ of appropriate media. From this cell suspension, $10 \mu \mathrm{L}$ was removed for counting using a microscope. Cell viability was tested by adding $10 \mu \mathrm{L}$ of cells to $10 \mu \mathrm{L}$ of trypan blue $0.4 \%$ (lonza, USA), $10 \mu \mathrm{l}$ of the mixture put on hemocytometer (Neubauer, Germany) and count cell under light microscope (Olympus CX31, USA).

Number of cells $/ \mathrm{ml}=$ average of counted cells $\times$ dilution factor $\times 1042 \times 106$ cells/rat. MSCs $(2 \times 106$ cells $/$ rat $)$ in 0.2 $\mathrm{ml}$ Dulbecco's modified Eagles medium (DMEM) filled in syringes and intravenous injected slowly through the dorsal penial vein per each rat after anaesthetized by a short-acting narcotic agent (Jiang et al. 2008) (Figure 2).

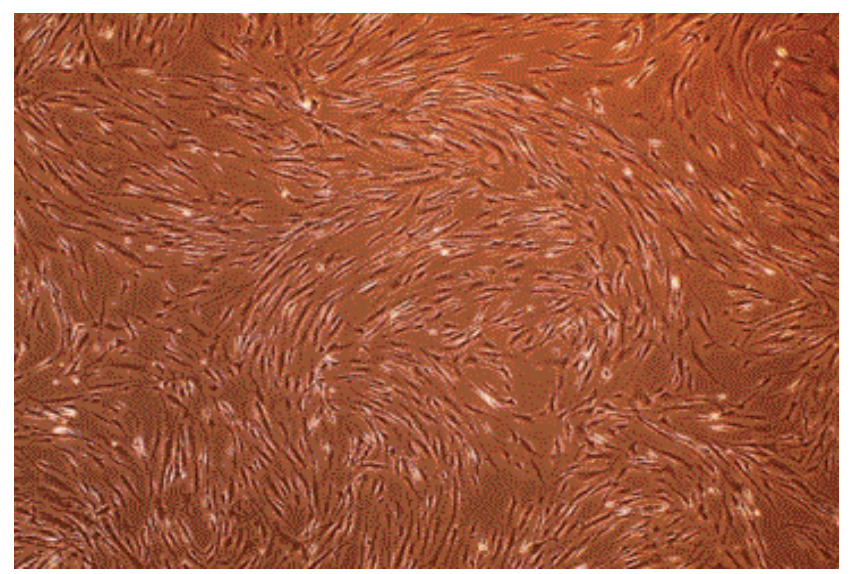

Figure 1: Morphology of mesenchymal stem cells, ten days after isolation $(\times 100)$ showing spindle shape fibroblast like cells. 


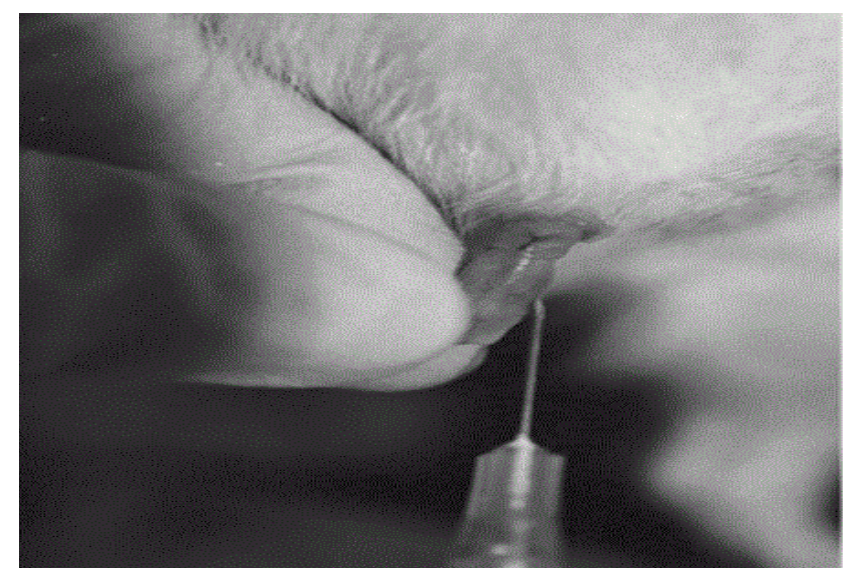

Figure 2: Showing the intravenous injection of MSCs in the dorsal vein of the penis of rats.

\section{Animal grouping}

Animals were divided into three groups each of 10 rats. Group 1 (normal healthy control group),this group has normal serum glucose level and were daily injected only with $0.2 \mathrm{ml}$ of $50 \mathrm{mM}$ sodium citrate solution (pH 4.5). Group 2 (diabetic group), the rats of this group were diabetic in which diabetes was induced by injection of $0.2 \mathrm{ml}$ of freshly prepared STZ $(45 \mathrm{mg} / \mathrm{kg})$ dissolved in $50 \mathrm{mM}$ sodium citrate solution and left non treated, just injected daily with $0.2 \mathrm{ml}$ of $50 \mathrm{mM}$ sodium citrate solution ( $\mathrm{pH} 4.5$ ). Group 3 (MSCs treated group), contain STZ diabetic induced rats and were received $(2 \times 106$ cells $/ \mathrm{rat})$ MSCs as treatment in $0.2 \mathrm{ml}$ Dulbecco's modified Eagles medium (DMEM) by intravenous injection through penial vein of rats.

\section{Sample collection}

After six weeks of MSCs transplantation in diabetic rats, the total duration period of the experiment, all animals were sacrificed by cervical decapitation after light isoflurane anesthesia. Blood samples were collected into plain gel tube and centrifuged at 5000 rounds per minute for $10 \mathrm{~min}$, obtained serum was pipetted off then stored at $-20^{\circ} \mathrm{C}$ until used for estimation of biochemical parameters.

Pancreas, liver and kidney organs were removed from 5 rats of each group and washed with $0.9 \% \mathrm{NaCl}$ isotonic solution for removing excess of blood on the tissues. The washed organs were fixed in $10 \%$ formalin and routinely processed to produce paraffin wax blocks. The obtained blocks were cut into sections using a microtome at $5 \mu \mathrm{m}$ thickness, stained with hematoxylin and eosin (HE) and examined under light microscope for histopathological finding (Luna et al. 1996).

\section{Determination of biochemical parameters}

Serum alanine transferase (ALT) and aspartate transferase (AST) activities, albumin, creatinine, glucose, and blood urea nitrogen levels were estimated in plasma by colorimetric methods as described by the manufacturer (EGY- CHEM for Lab Technology, Egypt) (Reitman et al. 1957). Serum alkaline phosphatase (ALP) was measured according to the commercial kit purchased from (AMS, U.K, Ltd., 42, Ballymena, Galgorm, Co.Antrim). Insulin level was measured by using enzyme-linked immune-sorbent assay (ELISA) supplied by (Thermo Scientific, USA) using the kit from (Mercodia AB, Uppsala,Sweden) (Judzewitsch et al. 1982). Malone Di aldehyde (MDA) was estimated by colorimetric assay using kits purchased from (Sigma-Aldich, Germany) on spectrophotometer (Photometer 5010, Riele $\mathrm{GmbH}$, Germany) (Ohkawa et al. 1979). Lipid profile of serum total cholesterol (TC), triglycerides (TG), low density lipoprotein (LDL) and high density lipoprotein (HDL) were estimated using colorimetric method as described by the manufacturer (Bio Diagnostic Co., Egypt) (Friedwald et al. 1972).

\section{Statistical analysis}

The resulted values were expressed as means \pm standard error (SE) for ten rats $(n=10)$ of each animal group. Table 1 and graphs were designed using Microsoft Excel software. Data were statistically analyzed using Statistical Package for Social Science (SPSS) version 18 software. One-Way Analysis of variance (ANOVA) followed by student t-test were performed for determining the statistically significant differences between groups. Differences were considered to be statistically significant when the $\mathrm{P}$ values were $\leq 0.05$.

\section{RESULTS}

\section{Glucose concentration and serum insulin levels}

Serum glucose was significantly increased in diabetic group $(308.7 \pm 8.31)$ comparing to control group $(118.3 \pm 3.35)$ and significantly decreased in diabetic stem cell transplanted group (187 \pm 7.91$)$ compared to diabetic group. On the other hand, serum insulin was significantly decreased in diabetic group (10.4 \pm 0.6$)$ comparing to control group $(25.9 \pm 1.24)$ and significantly increased in stem cell transplanted group (19.4 \pm 0.67$)$ compared to diabetic group (Figure 3).

Total cholesterol, serum high density lipoprotein (HDL), serum low density lipoprotein (LDL) and triglycerides (TG) concentration

Serum total cholesterol, LDL, and triglyceride levels showed significant increase in diabetic group $(151 \pm 3.6,39.9 \pm$ 1.23 , and $95.7 \pm 2.96)$ compared to control group (109.4 \pm $3.54,29 \pm 0.71$, and $77.7 \pm 2.56$ ). Conversely, in the stem cell transplantation treated group they were decreased $(128.7 \pm 2.99,29.3 \pm 1.61$, and $84.3 \pm 1.71)$ compared to diabetic group. Serum HDL was significantly decreased in the diabetic group $(40.6 \pm 1.5)$ compared to the control group $(56.4 \pm 1.88)$ and significantly increased in stem cell transplantation treated group $(45.5 \pm 1.92)$ in the comparison with the diabetic group.

\section{Malondialdehyde (MDA) and alkaline phosphatase (ALP)}

Serum MDA and ALP were significantly increased in diabetic group ( $4.6 \pm 0.3$ and $70.6 \pm 2.4)$ compared to control group ( $2.02 \pm 0.1$ and $28.8 \pm 0.93)$. On the other hand they were significantly decreased in stem cell transplanted group (2.66 \pm 0.12 and $38.6 \pm 1.32$ ) compared to diabetic group (Figure 4).

\section{Alanine aminotransferase (ALT) and aspartate aminotransferase (AST)}

Serum ALT and AST levels revealed significant increase in 
the diabetic group $(98.5 \pm 4.25$ and $82.3 \pm 2.8)$ compared with the control group $(55.5 \pm 2.69$ and $54.8 \pm 2.67)$ and significant decrease in stem cell transplantation treated group $(72 \pm 2.64$ and $74.3 \pm 1.88$ ) versus diabetic group (Figure 5 and 6).

\section{Serum creatinine and blood urea nitrogen (BUN)}

Serum creatinine and BUN were significantly increased in diabetic group $(3.11 \pm 0.1$ and $90 \pm 2.32)$ when compared with control group $(1.39 \pm 0.25$ and $56.8 \pm 2.73)$ while they were significantly decreased in stem cell transplantation treated group $(2.68 \pm 0.17$ and $73.8 \pm 2.54)$ in comparison with the diabetic group (Figure 7).

\section{Histopathological findings}

Microscopic examination of the pancreas sections of the normal control rats showed normal exocrine acinar structure and spherical shaped islets of Langerhans with well-defined edges of connective tissue and rounded islet cells. The pancreatic sections of the diabetic rats revealed extensive destruction of Langerhans islets. The islets had ill-defined boundaries and some necrotic areas were often noticed. Also, massive inflammatory cell infiltrations were observed and the islets had vacuolization with cytoplasmic secretions. The pancreatic sections of the diabetic rats treated with MSCs showed that the islets with non-well-developed boundaries. Necrotic cells couldn't noticed, the islet cells have vesicular eosinophilic stained cytoplasm and degeneration had greatly ameliorated. Histopathological examination of the liver tissue of the normal control group showed normal hepatic architecture. Hepatocytes are arranged in lobules. Hepatocytes of the diabetic group were severely necrotic, degenerated and congested. Infiltration with inflammatory cells and hemorrhage in hepatic sinusoids could be seen. The liver of diabetic MSCs treated group showed moderate necrosis and few apoptotic bodies could be seen. Hepatocytes showed moderate hydropic degeneration with restored normal lobular architecture and mild inflammatory infiltrate.
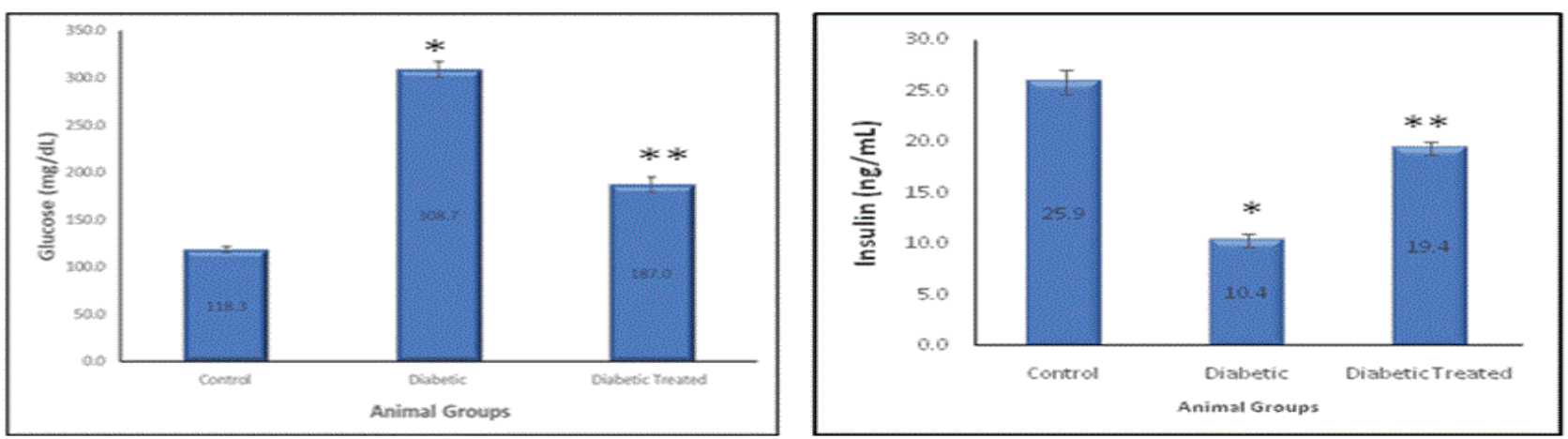

Figure 3: The effect of MSCs transplantation on serum glucose concentration and insulin level of diabetic rat. Data are presented as mean $\pm \mathrm{SE}(\mathrm{n}=10) .\left(^{*}\right)$ indicate significant differences versus normal control and $\left({ }^{* *}\right)$ refer to significant differences versus diabetic animals at $P<0.05$ using one way ANOVA followed by Tukey-t test.
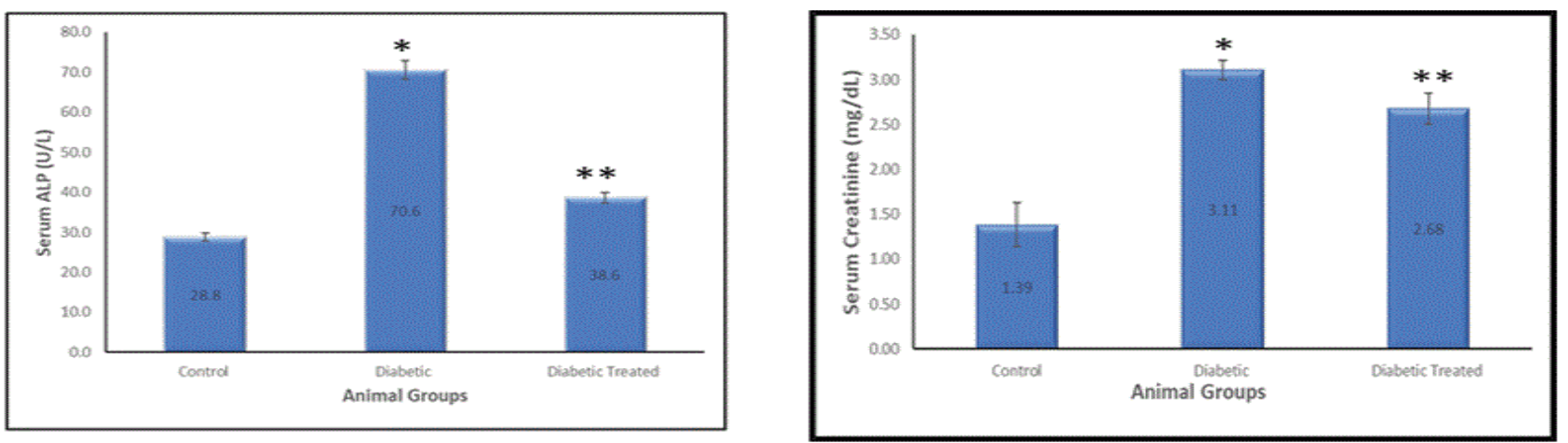

Figure 4: The effect of MSCs transplantation on serum MDA level and ALP activity of diabetic rat. Data are presented as mean \pm SE $(\mathrm{n}=10)$. $\left(^{*}\right)$ indicate significant differences versus normal control and $\left(^{* *}\right)$ refer to significant differences versus diabetic animals at $P<0.05$ using one way ANOVA followed by Tukey-t test.

Table 1: Effect of MSCs transplantation on biochemical parameters after six weeks of treatment in STZ diabetic induced rats.

\begin{tabular}{|l|c|c|c|c|c|c|c|c|}
\hline Groups/Parameters & Cholesterol & TG & HDL & LDL & ALT & AST & Creatinine & BUN \\
\hline Control & $109 \pm 3.5$ & $77.7 \pm 2.5$ & $56 \pm 1.8$ & $29 \pm 0.71$ & $55 \pm 2.6$ & $54 \pm 2.6$ & $1.39 \pm 0.25$ & $56.8 \pm 2.7$ \\
\hline Diabetic & $151 \pm 3.6^{*}$ & $95 \pm 2.9^{*}$ & $40.6 \pm 1.5^{*}$ & $39 \pm 1.2^{*}$ & $98 \pm 4.2^{*}$ & $82 \pm 2.8^{*}$ & $3.1 \pm 0.1^{*}$ & $90 \pm 2.3^{*}$ \\
\hline MSCs Transplanted & $128 \pm 2.9^{* *}$ & $84 \pm 1.7$ & $45 \pm 1.9$ & $29 \pm 1.6^{* *}$ & $72 \pm 2.6^{* *}$ & $74 \pm 1.8$ & $2.6 \pm 0.17$ & $73 \pm 2.5^{* *}$ \\
\hline
\end{tabular}




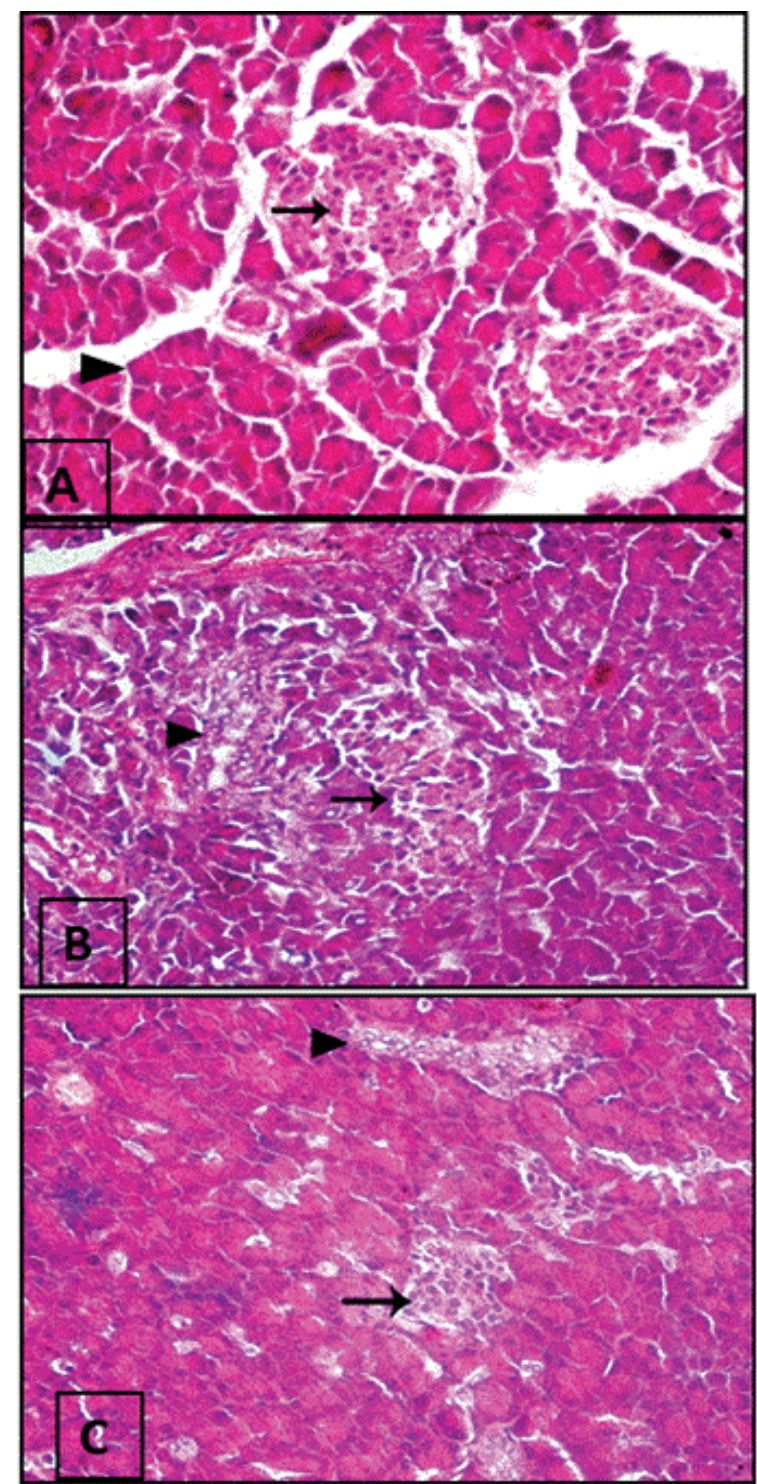

Figure 5: T.s in the pancreas of different animal groups. A. Normal control group showing spherical shaped islets of Langerhans (arrow) with rounded $\beta$-cells and normal exocrine portion (arrow head). B. Diabetic non treated group showing a degeneration of islets of Langerhans (arrow), hyperplasia of lining epithelium in intralobular pancreatic duct (arrow head). C. diabetic MSCs treated group showing regeneration of islets of Langerhans and $\beta$-cell (arrow) with normal exocrine portion. Sections are Hematoxylin Eosin stained and magnification power is (400x).

Kidney structure of the normal control group showed normal structure of renal glomeruli and tubules. Diabetic non treated group showed marked degeneration of tubular epithelium and intertubular areas of hemorrhage. Diabetic MSCs treated group demonstrated minimal hydropic degeneration of tubules epithelia with moderate congestion.

\section{DISCUSSION}

The currently used antidiabetic chemical derived medical therapies may be acting on insulin resistance such as metformin, whereas the other treatments are targeting on $\beta$-cells dysfunction or mass such as pioglitazone and glucagon like peptide-1 (GLP-1) agonistic analogue. However, GLP-1 group revealed a great success in islet neogenesis experimentally only and have not achieve the same desired
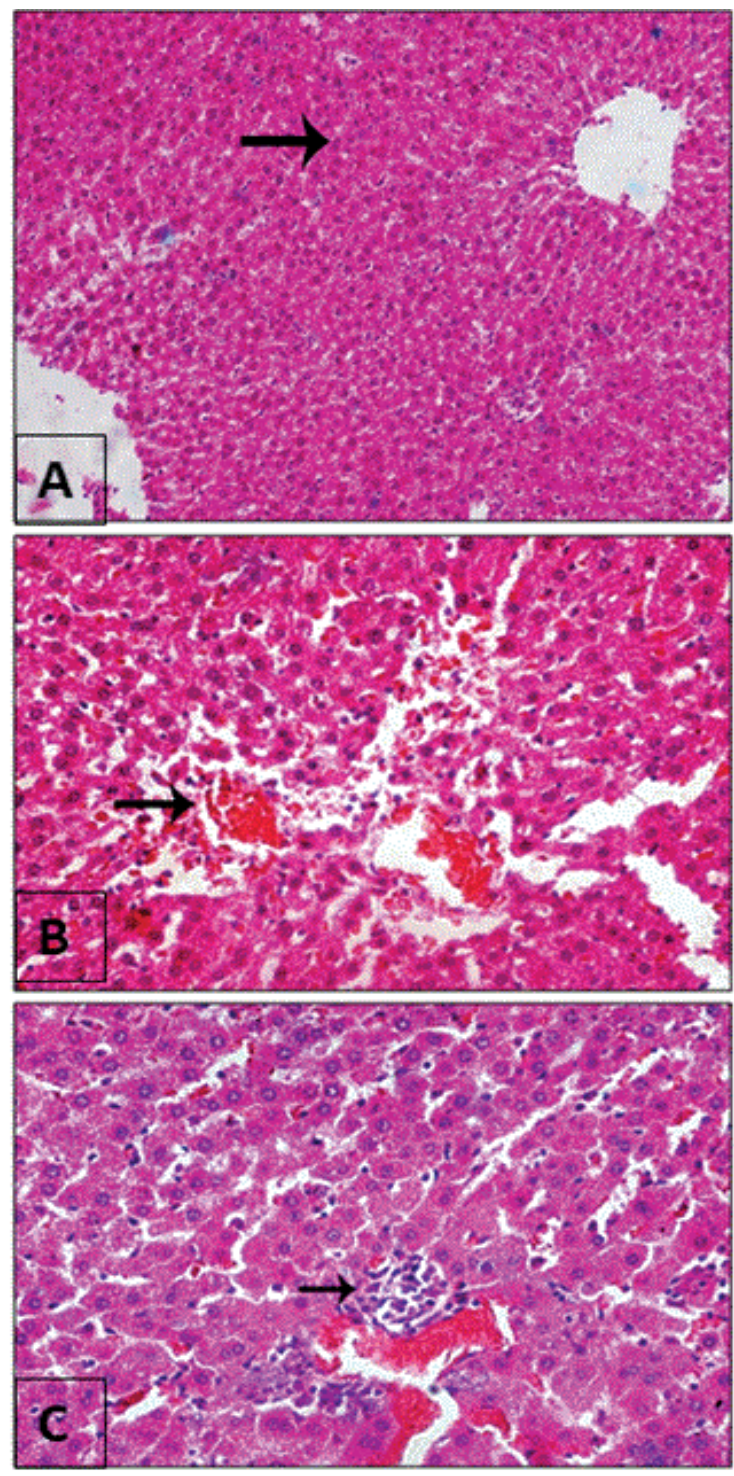

Figure 6: T.s in the liver of different animal groups. A. Normal control group showing normal hepatocytes arranged in lobules (arrow) and normal hepatic architecture. B. Diabetic non treated group showing necrosis of hepatocytes with severe congestion and hemorrhage in hepatic sinusoids. C. Diabetic MSCs treated group showing mild lymphocytic infiltrate (arrow), and normal hepatocytes and hepatic arctexture. Sections are Hematoxylin Eosin stained and magnification power is (100x).

effects or have limited efficacy in humans (Portha et al. 2011).

Therefore, there are great interest in the cell based treatment therapies like mesenchymal stem cells transplantation even derived from bone marrow or placenta in the treatment and management of diabetes (Jiang et al. 2011).

The cultured MSCs in the current work were characterized by their adhesiveness and spindle shape, which was in agreement with those findings of Aziz et al. 2013. On another hand, LiBo et al reported that the MSCs could be differentiating in vitro into pancreatic islet beta-like cells successfully and the differentiated cells were similar in shape to that of pancreas (Bo et al. 2004). The current work focused on the potential role of treatment with MSCs on the $\beta$-cells neogenesis and functioning. However, the chronic hyperglycemia resulting 

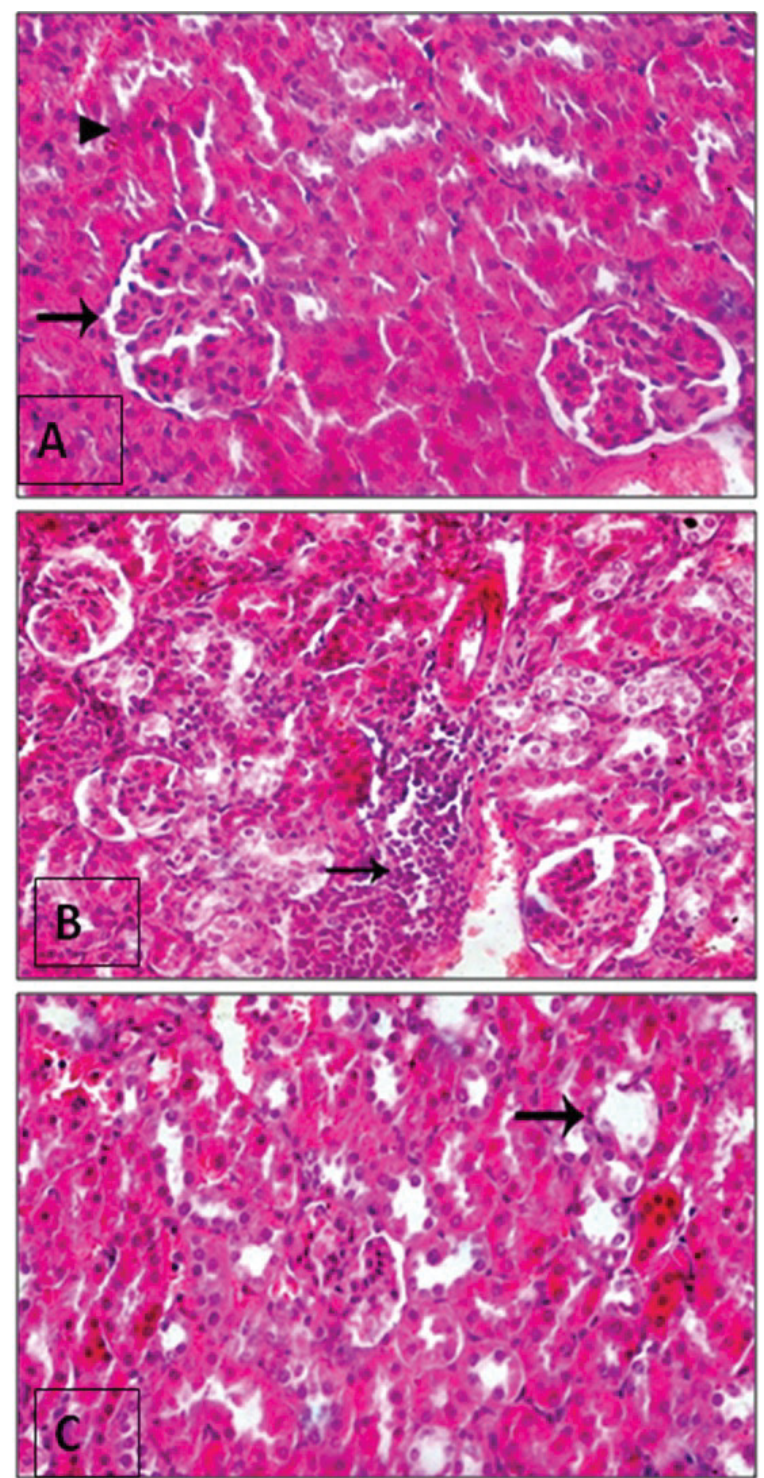

Figure 7: T.s in the kidney of different animal groups. A. Normal control group showing normal renal glomeruli (arrow), with normal tubular cells. B. Diabetic non treated group showing intense lymphoplasmocytic exudate in interstitial tissue (arrow) and tubular degeneration. C. Diabetic MSCs treated group showing mild degenerative change in renal tubular lining renal epithelium (arrow). (HE, 400x) Sections are Hematoxylin Eosin stained and magnification power is (400x).

from diabetes can lead to irreversible damage, dysfunction and failure of various organs (Barky et al. 2017). In the present study, the STZ treated group showed a significant increase in serum glucose levels accompanied with a significant decrease in serum insulin concentration when compared with the control group. These results could be due to the toxic effect of STZ which can induce a selective destruction of pancreatic beta cells (Zhang et al. 2003). The loss of beta-cell due to that destruction leading to a massive defect in insulin secretion and so hyperglycemia occurred. On another hand, there are a significant decrease in serum glucose concentration accompanied with a significant increase in serum insulin level were observed in the MSCtreated group. It was reported that treatment with MSCs are capable of dimensioned blood glucose levels in the diabetic animals (Jiang et al. 2011). These effects could be due to the therapeutic effects of MSCs on the islets restoration by their differentiation ability into functional insulin secreting beta cells after pancreatic damage caused by STZ and the insulin secretion increased leading to decreasing on glucose concentration (Bell et al. 2012). The improvement in the $\beta$ cell mass or function could be also attributed to the fusion of MSCs with $\beta$-cells and reprogramming of both $\beta$-cells and MSCs nuclei allowing the insulin gene expression and increased $\beta$ - cells proliferation with dimensioned apoptosis (Yanai et al. 2013).

Data from the present work showed a significant increase in MDA, ALP, ALT, and AST levels in the STZ diabetic induced non treated group. The increased glucose levels may stimulate the production of free radical and could be the mechanism by which the oxidative stress and lipid peroxidation is increased (Salvayre et al. 2008). Moreover, ALP attributed to defense against the damage induced in the hepatic cells upon the toxic effect of STZ in diabetic rats (Shahjahan et al. 2004). This explanation was confirmed by the obtained results and the associated significant increase in the levels of liver-function enzymes ALT and AST (Giboney et al. 2005). Similarly, other cited studies decided the elevation on serum AST, ALT and ALP enzymes activities in the diabetic non treated animals may revert the damaging of the liver cells thought to be logical with their increased need for gluconeogenic substrates (Nanbora et al. 1990). In the same way, ALT, AST and ALP activities were increased due to hepatotoxic effect of STZ which leading to hepatorenal damage (Elsner et al. 2000). Conversely, the transplantation with MSCs in diabetic group showed a significant decrease in the levels of MDA, ALP, ALT, and AST in comparison with the nontreated diabetic animals which was in a full agreement with the results of Elyamani et al. 2017. The amelioration of the increased serum ALT, AST and ALP activities is suggested to be due to the capability of MSCs in the protection of the cells from the cytotoxic injury (Vitek 2012) and regeneration of hepatocytes following transplantation (Nasser et al. 2015). A study of Newman et al. 2009 have reported that the therapeutic potential of MSCs was attributed to their unique properties specially to damaged tissues by suppressing immune response and also the inflammatory response so facilitating the damaged tissues regeneration and repairing process (Newman et al. 2009). The immunomodulatory, anti-inflammatory and anti-apoptotic effects contributed to decreasing in oxidative stress reactions and lipid peroxidation pathways (Volarevic et al. 2011).

In the same way, creatinine and BUN levels were increased in the diabetic non treated group rats compared with normal control group. These results were in accordance with the study of Idonije et al. 2011. The increase level of BUN in STZ induced diabetic rats might be related to excessive protein catabolism. Madianov et al. (2000) proved the elevation BUN level in diabetic rats to the disturbance in metabolic activity which leads toincrease in lipid peroxidation, triglyceride and cholesterol (Volarevic et al. 2000).

Moreover, creatinine and BUN were significantly decreased after MSCs transplantation to diabetic animals. This decrease could be proved to integration of MSCs into damaged tubules 
and differentiate into renal cells in the cases of acute kidney injury (Morigi et al. 2004).

However, other studies showed protection from injury by exogenous MSCs with little or no tubular incorporation. This was consistent with other researchers who suggested that exogenous MSC.s paracrine activity may stimulate the endogenous renal stem cell population, leading to cellular recovery and renal injury repair (Busolati et al. 2008). The obtained data revealed that MSCs transplantation had ameliorated the impaired renal function in diabetic. This role of MSCs in treatment of diabetic nephropathy could be explained their differentiation into $\beta$-cells and decreasing of serum glucose level and glycosuria, that leading to renal cells damage (Hammam et al. 2015). In addition, Zhang et al. (2008) reported a significantly or moderately increased level of urea in diabetic rats and this relationship suggests enhanced amino acids-fuelled gluconeogenesis in diabetic rats that lead to increased nitrogen load to the liver where urea is formed.

Regarding lipid profile, the current results revealed a significant increase in serum total cholesterol, TG, and LDL concentrations with a significant decrease in the HDL concentration in the diabetic untreated group by comparing with normal control group. Otherwise, transplantation of diabetic rats with MSCs had significantly diminished the raised lipid profile serum total cholesterol, TG and LDL with increased HDL concentration. The decrease of lipid profile parameters might relate with the action of MSCs which reduces the hyperglycemia and their ability in the increase of serum insulin which leading to the activation of lipoprotein lipase (El-Said et al. 2018).

Although stem cells transplantation considered as a promising therapeutic strategy for the treatment of diabetes, the safety of transplantation have not yet been well defined. However, further and more specific researches are needed to confirm these finding especially prior to be used in clinical application (Liao et al. 2016). Histopathological examination showed marked damage and inflammatory responses in the diabetic non treated group due to the toxic effects of STZ and the complications of diabetes. An improvement in the tissues of pancreas, liver and kidney of diabetic animals after treatment with MSCs was markedly noticed. This improvement was in a strong harmony with the biochemical finding in which all of the parameters of organs functions were ameliorated.

\section{CONCLUSION}

The treatment of diabetic induced rats with MSCs transplantation had the ability in lowering blood glucose level when compared diabetic untreated group after six weeks of treatment. Moreover, biochemical and histological finding revealed that there is noticeable improvement in pancreatic islets of Langerhans accompanied with more insulin released from islets $\beta$-cell. The study recommended further studies in different animals and different doses to assess the most ideal form of treatment and how to be applicable at human wise base.

\section{REFERENCES}

1. Chhabra, P. and Brayman, K. L. (2013) Stem cell therapy to cure type 1 diabetes: from hype to hope. Stem. Cells. Transl. Med., 2: 328-336.

2. Bhansali, S., Vinod Kumar, V. and Dutta, P. 2015. Effect of mesenchymal stem cells transplantation on glycaemic profile and their localization in streptozotocin induced diabetic Wistar rats. Indian. J. Med. Res. 142: 63-71.

3. Ahmed, I., Nasren, S., Jehangir, U., and Wahid, Z. 2017. Frequency of oral lichen planus in patients with noninsulin dependent diabetes melitus. Journal of Pakistan Association of Dermatology., 2: 30-34.

4. Lv, C. L., Wang, J., Xie, T., and Ouyang, J. 2014. Bone marow transplantation reverses new-onset immunoinflammatory diabetes in a mouse model. Int. J. Clin. Exp. Pathol., 7: 5327.

5. Cantarelli, E., Pellegrini, S., Citro, A., Sordi, V. and Piemonti, L. 2015. Bone marrow- and cord blood-derived stem cell transplantation for diabetes therapy. CellR4., 3: $1-21$.

6. Byrne, C. D. and Targher, G. 2016. Clinical Practice Guidelines for the management of non-alcoholic fatty liver disease: Is universal screening appropriate? Diabetologia., 59: 1141-1144.

7. Lui, H., Tang, W. and Li, C. 2015. CdSe/ZnS Quantum dots-labeled mesenchymal stem cells for targeted fluorescence imaging of pancreas tissues and therapy of type 1 diabetic rats. Nanoscale Research Letters., 10: 1-12.

8. Franchi, S., Castelli, M., Amodeo, G., Niada, S., Ferrari, D., Vescovi, A. 2014. Adult stem cell as new advanced therapy for experimental neuropathic pain treatment. Biomed. Res. Int., 2014:470983.

9. Zhu, D., Chen, L., Hong, T. 2012. Position Statement of the Chinese Diabetes Society regarding stem cell therapy for diabetes. J. Diabetes., 4:18-21.

10. Portha, B., Tourrel-Cuzin, C., Movassat, J. 2011. Activation of the GLP-1 receptor signalling pathway: a relevant strategy to repair a deficient beta-cell mass. Exp. Diabetes. Res., 2011: 376509.

11. Hsiao, C. H., Qian Ji A. T., Chang C. C., Cheng, C. J., Lee, L. M. and Chun Ho, J. H. 2015. Stem. Cell. Res. Ther., 6:113.

12. Tariq, M., Masoud, M. S., Mehmood, A, Khan, S. N. and Riazuddin S. 2013. Stromal cell derived factor-1alpha protects stem cell derived insulin-producing cells from glucotoxicity under high glucose conditions in-vitro and ameliorates drug induced diabetes in rats. J. Transl. Med., 11:115.

13. Aziz, M. T., Atta, H., Mahfouz, S., Fouad, H. H., Roshdy, N. K., Ahmed, H. H., et al. 2007. Therapeutic potential of bone marrow-derived mesenchymal stem cells on experimental liver cirrhosis. Clin. Biochem., 40: 893-899.

14. Jiang, C. Y., Gui, C., He, A., Hu, X. Y., Chen, J., Jiang, Y., et al. 2008. Optimal time for mesenchymal stem cell transplantation in rats with myocardial infarction. J. Zhejiang. Univ. Sci. B., 9: 630-637. 
15. Luna, L. G. 1996. Manual of histological technique methods of armed forces. London: Institute of Pathology., $1-31$.

16. Reitman, S. and Frankel, S. 1957. A calorimetric method for the determination of serum GOT and GPT. Am. J. Clin. Pathol., 28: 56-63.

17. Judzewitsch, R. G, Pfeifer, M. A, Best, J. D, Beard, J. C., Halter, J. B, and Porte, Jr. 1982. Chronic Chlorpropamide therapy of noninsulin-dependent diabetes augments basal and stimulated insulin secretion by increasing islet sensitivity to glucose. J. Clin. Endocrino. Metab., 55: 321-328.

18. Ohkawa, H., Ohishi, N.,and Yagi, K. 1979. Assay for lipid peroxides in animal tissues by thiobarbituric acid reaction. Analytical biochemistry., 95: 351-358.

19. Friedwald, W. T, Levy, R. I. and Fredrickson, D. S. 1972. Estimation of the concentration of low density lipoprotein cholesterol in plasma without use of the preparative ultracentrifuge. Clin. Chem., 18: 499-502.

20. Jiang, R., Han, Z., Zhuo, G., Qu, X., Li, X., Wang, X., et al. 2011. Transplantation of placenta-derived mesenchymal stem cells in type 2 diabetes: a pilot study. Front. Med., 5: 94-100.

21. Aziz, M. T., Atta, H. M., Samer, H., et al. 2013. Heme oxygenase effect on mesenchymal stem cells action on experimental Alzheimer's disease. Excli. J., 12: 778-792.

22. Bo, L. C., Xiao-Bing, J., Lian, Y. 2004. Differentiation of rat marrow mesenchymal stem cells into pancreatic islet beta-cells. World. J. Gastroenterol., 10: 3016-3020.

23. El Barky, A. R., Hussein, S. A., Alm-Eldeen, A. A., et al. 2017. Saponins and their potential role in diabetes mellitus. Diabetes. Manag., 7: 148-158.

24. Zhang, F., Ye, C., Li, G., Ding, W., Zhou, W., et al. 2003. The rat model of type 2 diabetic mellitus and its glycometabolism characters. Exp. Anim., 52: 401-407.

25. Jiang, R., Han, Z., Zhuo, G., Qu, X., Li, X., et al. 2011. Transplantation of placenta-derived mesenchymal stem cells in type 2 diabetes: A pilot study. Front. Med., 5: 94 100 .

26. Bell, G. I., Broughton, H. C., Levac, K. D., Allan, D. A., Xenocostas, A., Hess, D. A. 2012. Transplanted human bone marrow progenitor subtypes stimulate endogenous islet regeneration and revascularization. Stem. Cells. Dev., 21: 97-109.

27. Yanai, G., Hayashi, T., Zhi, Q., Yang, K. C., Shirouzu, Y., Shimabukuro, T, et al. 2013. Electrofusion of mesenchymal stem cells and islet cells for diabetes therapy: a rat model. PLoS One. 8: e64499.

28. Salvayre, A. N., Coatrieux, C., Ingueneau, C., and Salvayre, R. 2008. Advanced lipid peroxidation end products in oxidative damage to proteins. Potential role in diseases and therapeutic prospects for the inhibitors. Br. J. Pharmacol., 153: 6-20.
29. Shahjahan, M., Sabitha, K. E., Jainu, M., and Devi, C. S. 2004. Effect of Solanum trilobatum against carbon tetrachloride induced hepatic damage in albino rats. Indian. J. Med. Res., 120: 194.

30. Giboney, P.T., 2005. Mildly elevated liver transaminase levels in the asymptomatic patient. Am. Fam. Physician., 71: $105-110$.

31. Nanbora, S., Tanaka, K., Koide, H., Tanaka, T. and Hayashi, T. 1990. Changes on levels of B6 vitamin and aminotransferase on the liver of diabetic animals. Diabetes. Res. Clin. Pract., 9: 109-121.

32. Elsner, M., Guldbake, B., Tiedge, M., Munday, R., and Lenzen, S. 2000. Relative importance of transport and alkylation for pancreatic beta-cel toxicity of streptozotocin. Diabetologia., 43: 1528-1553.

33. Elzawahry, E., Salem, M., Sayed Bakry, S., Rashed, L. and Husein, S. A. 2017. The role of stem cels and vitamin $\mathrm{D}$ in the atenuation of liver and kidney functions in STZinduced diabetic rats: Biochemical study. Int. J. Adv. Res. Biol. Sci., 4: 19-132.

34. Vitek, L. 2012. The Role of Bilrubin in Diabetes, Metabolic Syndrome, and Cardiovascular Diseases. Front. Pharmacol., 3: 5.

35. Nasser, H. G., Mohammad, A. E., Masoud, D., Leila, R., Maryam, A., Nosratollah, Z., et al. 2015. Improvement of liver cell therapy in rats by dietary stearic acid Iran. Biomed. J., 20: 217-222.

36. Newman, R. E., Yoo, Di., El Rou, X., Miagkora, A. 2009. Treatment of inflammatory disease with mesenchymal stem cells. Inflamm. Allergy. Drug. Targets., 8: 10-12.

37. Volarevic, V., Arsenijevic, N., Lukic, M. L. and Stojkovic, M. 2011. Mesenchymal stem cell treatment of complications of diabetes mellitus. Stem. Cells., 29: 5-10.

38. Idonije, B. O., Festus, O., and Oluba, O. M. 2011. Plasma glucose, creatinine and urea levels in type 2 diabetic patients attending a Nigerian teaching hospital. Res. J. Med. Sci., 5: 1-3.

39. Madianov, I. V., Balabolkin, M. I., Markov, D. S. and Markova, T. N. 2000. Main causes of hyperuricemia in diabetes melitus. Ter. Arkh., 72: 5-58.

40. Morigi, M., Imberti, B., Zoja, C., Corna, D., Tomasoni, S., Abate, M. and Alison, M. 2004. Mesenchymal stem cels are renotropic, helping to repair the kidney and improve function in acute renal failure. J. Am. Soc. Nephrol., 15: 1794-1804.

41. Busolati, B., Teta, C., and Camusi, G. 2008. Contribution of stem cells to kidney repair. Curr. Stem. Cell. Res. Ther., 28: 813-882.

42. Hammam, O. A., Shaker, O. G., Nasar, Y. H. and Ashour, S. S. 2015. Efect of Mesenchymal Stem Cells on Diabetic Nephropathy in Experimental Animals. Med. J. Cairo Univ., 83: 113-112.

43. Zhang, S., Gowda, G. N., Asiago, V., Shanaiah, N., Barbas, 
C., and Raftery, D. 2008. Corelative and quantiative $1 \mathrm{H}$ NMR-based metabolomics reveals specific metabolic pathway disturbances in diabetic rats. Anal. Biochem., 383: 76-84.

44. El-Said, K. S., Ezz, A. A. H., El Barky, A. R. and Mohamed, M. T. 2018. The potential role of male bone marrow mesenchymal stem cells of diabetic female rats. Diab. Manag., 8: 137-146.

45. Liao, N., Pan, F., Wan, Y., Zheng, Y., Xu, B.,Wenwei Chen, W., Gao, Y., Zhixiong Cai, Z., Liu, X., andLiu, J., 2016. Adipose tissue-derived stem cells promote the reversion of non-alcoholic fatty liver disease: An in vivo study. Int. J. Mol. Med., 37: 1389-1396. 